\title{
PATTERN OF ANTIMICROBIAL SUSCEPTIBILITY FOR SALMONELLA TYPHI IN DHAKA MEDICAL COLLEGE HOSPITAL FROM 2013-2014.
}

\author{
NAHAR SS ${ }^{1}$, RASHID A ${ }^{2}$, CHOWDHURY SS $^{3}$, BEGUM A ${ }^{4}$, AKTER N ${ }^{5}$, KHATUN K ${ }^{6}$, \\ SHAMSUZZAMAN SM ${ }^{7}$
}

\begin{abstract}
Multidrug resistant Salmonella spp has been emerged as a cause of concern. This study was done to evaluate recent status in antimicrobial susceptibility pattern of Salmonella typhi isolated from blood in Dhaka Medical college Hospital.

Methods- The retrospective study was done over a two year period between January 2013 to December 2014 at Microbiology laboratory, Dhaka Medical College. A total of 203 isolates of Salmonella typhi obtained from blood cultures. Both the indoor and outdoor patients were enrolled in this study.

Results- During the two year study period, total 203 cases were enrolled. Among them 66\% were male with a male to female ratio 2:1. The bulk (55\%) cases were in the age group of 15-30 years, 34\% cases were in less than 15 years and 10\% cases were between the ages of 31-45 years. Regarding antibiotic sensitivity pattern, $90.14 \%$ strains were sensitive to amikacin, 90.47\% to gentamycin and amoxyclav. $89.16 \%$ to doxycycline, $83.75 \%$ to cotrimoxazole, $71.42 \%$ to azithromycin and $86.2 \%$ to ceftazidime. All the Salmonella were sensitive to ceftriaxone, 95.07\% were sensitive to ciprofloxacin and $88 \%$ were nalidixic acid resistant Salmonella typhi (NARST).

Conclusion-Ceftriaxone may be used to treat typhoid fever cases and quinolone has no longer efficacy to treat such cases. Azithromycin may be used as an alternative drug if it is found susceptible in culture and sensitivity testing.
\end{abstract}

Key words: Antibiotic susceptibility, Bangladesh, Dhaka, Salmonella, Typhoid fever.

J Dhaka Med Coll. 2016; 25(2) : 115-118

\section{Introduction}

Enteric fever continues to be an important infection in South East Asia and travellers to these area. The different species of Salmonella are transmitted by faeco-oral routes in our country with poor standard of hygiene and sanitation which account for high morbidity and mortality. ${ }^{1}$ It affects 6 million people worldwide with more than 600,000 deaths a year. ${ }^{2}$ Almost $80 \%$ of the cases and deaths are in Asia and the rest occur mostly in Africa and Latin America. ${ }^{3}$ The incidence of enteric fever is increasing in many parts of the world, still it remains a public health problem in tropical countries. ${ }^{4}$ In regions where typhoid is endemic, clinical diagnosis becomes very difficult due to other prevalent overlapping infectious diseases like malaria, dengue fever and other viral diseases. Because of the difficulties in preventing typhoid fever by public health measures or immunization in developing countries, great reliance is placed on antimicrobial chemotherapy. 5

Nalidixic acid resistant Salmonella typhi with decreased susceptibility to ciprofloxacin is now

1. Dr. Sultana Shazeda Nahar, Assistant Professor, Department of Microbiology, Dhaka Medical College, Dhaka.

2. Dr. Aliya Rashid, Associate Professor, Department of Shaheed Suhrawardy Medical College, Dhaka

3. Dr. Sagana Shahreen Chowdhury, Lecturer, Department of Anatomy, Dhaka Medical College, Dhaka

4. Dr. Ayesha Begum, Assistant Professor, Department of Virology, Dhaka Medical College, Dhaka

5. Dr. Nadira Akter, Lecturer, Department of Microbiology, Dhaka Medical College, Dhaka

6. Dr. Khadeza Khatun, Assistant Professor, Department of Microbiology, Sir Salimullah Medical College, Dhaka 7. Dr. S.M. Shamsuzzaman, Professor and Head, Department of Microbiology, Dhaka Medical College, Dhaka

Correspondence: Dr. Sultana Shazeda Nahar, Assistant Professor, Department of Microbiology, Dhaka Medical College, Dhaka, Phone: 01720038310, E-mail: sultananahar97@gmail.com.

Received: 15 July 2016

Accepted: 01 September 2016 
endemic in India and neighboring countries. ${ }^{2}$ Failure to treat an infection properly leads to prolong illness, thus increasing the chance of developing a carrier state in which persons are contagious and able to spread the resistant strain to others. ${ }^{1}$

The present study was undertaken to reevaluate the trends of antibiogram of Salmonella typhi isolates, so that therapeutic value of common drugs and the empirical treatment of typhoid fever can be rationalized.

\section{Methodology}

A retrospective analysis of laboratory records from Dhaka Medical College microbiology laboratory was carried out. During 2 year study period from January 2013 to December 2014, total 203 subjects were enrolled. After taking antiseptic measures $5-10 \mathrm{ml}$ venous blood was collected from each patients and innoculated in tryptica soya broth or automated blood culture machine (BACTEC, Becton Dickinson). Subculture was done on blood agar and Mac Conkey's agar media. Salmonella typhi were identified by observing pale colonies on Mac Conkey's agar media and biochemical tests such as negative oxidase, urease and indole, alkaline slant and acid butt in TSI media with production of $\mathrm{H}_{2} \mathrm{~S}$, negative citrate utilization test and positive motility test. Final species were identified by specific antisera. Antimicrobial susceptibility test was done by the disc diffusion method (Kirby-Bauer technique) using Mueller Hinton agar media following CLSI, 2013.

\section{Result}

Majority of patients were male 133 (66\%) and $70(34 \%)$ were female, male to female ratio $2: 1$. The bulk 111 (55\%) cases were in the age groups $15-30$ years, 69 (34\%) of cases were less than 15 years, $20(10 \%)$ cases were $31-45$ years and $1 \%$ were more than 45 years of age. Proportion of resistance to ciprofloxacin was $4.93 \%$, nalidixic acid $87.65 \%$, azithromycin $28.58 \%$ and $100 \%$ were sensitive to ceftriaxone (Table-1).
Table-I

Antimicrobial sensitivity pattern of Salmonella typhi $(N=203)$

\begin{tabular}{lcc}
\hline Antibiotics & $\begin{array}{c}\text { Sensitive } \\
\mathrm{n}(\%)\end{array}$ & $\begin{array}{c}\text { Resistant } \\
\mathrm{n}(\%)\end{array}$ \\
\hline Amikacin & $183(90.14)$ & $20(9.86)$ \\
Amoxiclav & $184(90.47)$ & $19(9.53)$ \\
Azithromycin & $145(71.42)$ & $48(28.58)$ \\
Ceftazidime & $175(86.20)$ & $28(13.80)$ \\
Ceftriaxone & $203(100)$ & $0(0)$ \\
Ciprofloxacin & $193(95.07)$ & $10(4.93)$ \\
Cotrimoxazole & $170(83.75)$ & $33(16.25)$ \\
Doxycycline & $181(89.16)$ & $22(10.84)$ \\
Gentamycine & $184(90.47)$ & $19(9.53)$ \\
Nalidixic acid & $25(12.32)$ & $178(87.68)$ \\
\hline
\end{tabular}

Discussion

Typhoid fever is highly endemic in developing countries like Bangladesh and is an important cause of health problem involving huge health care costs, high morbidity and economic loss. ${ }^{6,15}$ In this study most of the Salmonella typhi were sensitive to cotrimoxazole. Ampicillin, chloramphenicol and cotrimoxazole are not being used to treat of typhoid fever cases for the last one decade and susceptibility to these drugs is reappearing in Salmonella. ${ }^{17}$ High susceptibility to cotrimoxazole, chloramphenicol were also reported from several parts of India such as Chennai and northern west. ${ }^{7}$ Study revealed reemergence of susceptibility to chloramphenicol and cotrimoxazole in great proportion. ${ }^{8,11}$

Multi drug resistant Salmonella emerged due to frequent use of first line of drugs. Then ciprofloxacin were started to use but within few years resistant strains of ciprofloxacin also emerged. Development of resistance to ciprofloxacin might be due to the fact that it is a orally taken antibiotic, effective against many gram positive and gram negative bacteria and can be taken twice daily, for this it is being widely used. Moreover antibiotics are sold over the counter and people can buy it for minor illness for which it is not actually needed and the drug seller often offer ciprofloxacin as an alternative to other drugs. 
In this study, sensitivity to ciprofloxacin was 95\% and NARST $88 \%$. Salmonella typhi strains with reduced susceptibility to fluroquinolone have become major health problem in Asia and other parts of world. In present study all of NARST had good sensitivity to ciprofloxacin which correlate with the data of another study. ${ }^{12}$ Ciprofloxacin which showed good sensitivity in vitro was not effective in vivo if the isolate was nalidixic acid resistant. ${ }^{9}$ It was advised to use nalidixic acid sensitivity testing for deciding treatment with fluroquinolones as the isolate that are nalidixic acid resistant may not show response in vivo with fluroquinolone even though the strain is sensitive to it in vitro. World Health Organization (WHO) recommended that azithromycin or the third generation of cephalosporin or a 10-14 days course of high dose fluroquinolones for the treatment of nalidixic acid resistant typhoid (NART). ${ }^{6,18}$

In this study all the 203 isolates were sensitive to ceftriaxone which correlates with other data. ${ }^{6,10,13}$ So dependence is now on $3^{\text {rd }}$ generation cephalosporin. But ESBL production is increasing in Salmonella from Bangladesh, India and Germany. ${ }^{19,21}$ However, ESBL production was not observed for Salmonella in this study. This emphasizes the importance of $3^{\text {rd }}$ generation cephalosporin like ceftriaxone as a reserve drug for treating multi drug resistant Salmonella typhi (MDRST) and ciprofloxacin resistant cases. ${ }^{1,18}$ Currently $3^{\text {rd }}$ generation cephalosporins and azythromycin are the only reasonable therapeutic options for most cases of travel related enteric fever. ${ }^{14,}$, 20 In our study azythromycin resistance is increasing (29\%) and it also correlates with other study. ${ }^{12,16}$

In the present study $100 \%$ Salmonella were sensitive to ceftriaxone which is the drug of choice in Dhaka Medical College and other parts of Bangladesh to treat typhoid fever. In Bangladesh so far no ceftriaxone resistant Salmonella has been identified.

\section{Conclusion}

Our antimicrobial susceptibility data suggests that ceftriaxone seem to be effective therapeutic options to treat typhoid fever in our region though judicious use is mandatory to prevent emergence of resistant strains.

\section{References}

1. Singhal, Gupta PK, Kale P, Gautam V, Raj P. Trends in antimicrobial susceptibility of Salmonella typhi from North India (2001-2012) Indian Jour of Med Microbiol 2014; 32(2):149-152.

2. Ray P, Sharma J, Mark R.S.K. and Garg R.K. Predictive efficacy of Nalidixic Acid resistance as a marker of Fluroquinolone resistance in salmonell R.K. a enterica var typhi. Indian J Med Res July 2006; 124: 105-108.

3. The world health report, Report of the Director General WHO, Geneva: World Health Organization; 1996.

4. Teh CS, Chua KH, Thong KL. Paratyphoid fever: splicing the global analysis; Int. J Med Sci 2014; May 14; 11(7): 732-41.

5. Kaurthe J. Increasing antimicrobial resistance and narrowing therapeutics in typhoidal Salmonella. J Clin Diagn Res 2013; 7(3): 576-9.

6. Begum A, Bari MS, Chowdhury FR, Ahmed N, Sayeed K. Pattern of antimicrobial sensitivity and resistance against Salmonella species in a tertiary hospital in Dhaka. Journal of Enam Med College 2015; 5(2): 88-92.

7. Kumar Y, Sharma A, Mani KR. Re- emergence of susceptibility to conventionally used drugs among strains of Salmonella typhi in central west India. $\mathrm{J}$ infect Dev Ctries 2011; 5(3): 227-230.

8. Chand HJ, Rizal KR, Neupane B, Sharma VK, Jha B. Re- emergence of susceptibility to conventional first line drugs in Salmonella isolates from enteric fever patients in Nepal. J infect Dev Ctries 2014; 8(11): 1483-1487.

9. Neopane A, Singh SB, Bhatta R, Dhital B, Karki DB. Changing spectrum of antibiotic sensitivity in enteric fever. Kathmandu Univer Medi Jour 2008; 6(1); 12-15.

10. Arora D, Gupta P, Gill G, Chawla R, Singla R, Changing trends in the antibiograms of Salmonella isolates in northern area of Punjab. International Journal of Pharmacy and Pharmaceutical science 2010; 2(supp13): 135-137.

11. Lakshmi V, Ashok R, Susmita J, Shailaja V V. Changing trends in the antibiograms of Salmonella isolates at a tertiary care hospital in Hyderabad, Indian J Med Microbial. 2006 Jan; 24(1): 45-8.

12. Akter T, Murshed M, Shahnaj S, Sarowar T, Duza SS, Begum T. Typhoidal Salmonella in Holy Family Red Crescent Medical College Hospital, Dhaka, Bangladesh. Bangladesh j Med Microbiol 2015; 9 (2): 13-16. 
13. AHMAD Q, Hossain MR, RAHMAN MM, Hossain $Z$, AHMAD UM. Pattern of antibiotic sensitivity in twenty bacteriologically proven cases of complicated typhoid fever. Bangladesh J Medicine 1994; 5: 42-44.

14. Metlzer E, Schwartz E. Enteric fever: a travel medicine oriented view, Curr Opin Infect. Dis. 2010 oct; 23 (5):432-7.

15. Background document: the diagnosis, treatment and prevention of typhoid fever, world health organization, 2003.

16. Vala S, Shah U, Ahmad SA, Scolink D, Glatstein M. Resistance pattern of typhoid fever in children: A Longitudinal Community-Based Study, Am J Ther. 2016; 23(5): e 1151-1154.

17. Rashid A, Rahman S HZ, Chowdhury A, Begum SA, Nahar SS, Islam KMS, Muazzem N. Laboratory diagnosis of enteric fever by blood culture and
Sensitivity Pattern of isolated Salmonella speices. J Dhaka Med. Coll. 2007; 16(2): 70-74.

18. Khan RM, Hoque. Emergence of multi-drug resistant Salmonella typhi: A need for Therapeutic reappraisal. Bangladesh $\mathrm{J}$ child health 1992; Vol. 16(112): 1-3.

19. Capoor MR, Nair D, Hasan AS, Aggarwal P, Gupta B. Typhoid fever: Narrowing therapeutic options in India, Southeast Asian J Trop Med public health 2006; 37: 1170-1174.

20. Ackers ML, Puhr ND, Tauxe RV, Mintz ED. Laboratory-Based Surveillance of Salmonella serotype Typhi infection in the United States. Antimicrobial resistance on the rise. JAMA 2000; vol 203, No 20: 2668-2673.

21. Pfcifer Y, Mahen J and Rabsch W. Salmonella Enterical serovar Typhi with CTX-M â- lactamase Germany. Emery infect Dis, 2009; 15(9): 15331535 . 